\title{
Research on Cultural Landscape in Yi Villages in Chuxiong Prefecture of Yunnan
}

\author{
Chunsuo Yang \\ School of Design, Yunnan Arts University, Kunming Yunnan, 650000, China
}

Key Words: Chuxiong, Yunnan, Yi Villages, Cultural Landscape

\begin{abstract}
The study on landscape architecture in China has seldom touched that of ethnic minorities for a long time, including that of the Yi ethnic group (an important ethnic minority in China). This phenomenon is not good for reflecting the richness of China's gardening culture, and has hampered the deep development of the research on gardening culture to a certain extent. Hence, making analysis and research by combining the historic culture and landscape architecture will enrich the theories of garden culture landscape of ethnic minorities in China, and promote the modern garden culture of China, which is of great significance and value for further research.
\end{abstract}

\section{Introduction}

The Yi ethnic group has a long history since its emergence. Throughout the long process of cultural evolution, Yi people, like other ethnic groups, have completed the development of their place of residence, creating rich and colorful culture, including language with ethnic characteristics, unique traditions of life and production, and village cultural landscape. The village cultural landscape has great significance in respect of artistic research of garden culture, and positive effect on the artistic research of garden culture of China. Under the context of urbanization, the research of the features and characteristics of the landscape and garden culture in Yi villages, and of their application in contemporary building construction will promote the deep exploration of landscapes with Yi characteristics, enrich Chinese garden art with the garden art of the Yi ethnic group, and boost the development of Chinese garden art.

\section{Current Situation of Local Culture Heritage of the Yi Ethnic Group in Chuxiong in Urbanization Process}

With the social change, the urbanization is proceeding in full swing around the country, and Chuxiong is no exception. More and more modern buildings are springing up, significantly affecting the development of local garden art and culture. Fortunately, the urbanization has not heavily damaged the Yi villages in Chuxiong, and a large amount of local culture heritages in the Yi villages are preserved well, which provides certain support and reference to the research of cultural landscape in the Yi villages in the new period. Some representative aspects of local culture heritages will follow below.

\section{Bimo Culture}

The primitive religious culture of Yi people was developed from the long history of social labor, production, and living practice of $\mathrm{Yi}$ people. Its core content is the worship to ancestors, supplemented by the worship to nature, ghosts and gods, and totem, which together formed a mysterious traditional spiritual belief. It is unique in the world. Bimo is the carrier of the religious culture of Yi people, has certain effect on the living, production, and spiritual temperament of Yi people, and has constituted a particular cultural structure of Yi people via constant evolution, which is widely called Bimo culture in the research community. Bimo culture is an important element of the traditional culture of Yi people, has abundant connotations, and affects the living and production of Yi people in multiple aspects ${ }^{[1]}$. As a whole, Bimo culture has been running through the development of the civilization of Yi people.

In the viewpoint of people in Chuxiong, Bimo is the spreader of social knowledge of the entire Yi group, and is of great significance in the inheritance of the spiritual culture of the Yi group. In Lifang 
Village, the inheritance and development of Bimo culture among the Yi people relies on apprenticeship. Figure 1 shows the sacrifice clothes in Bimo culture. The patterns of the clothes and sacrificial utensils reflect the connotation of Bimo culture.

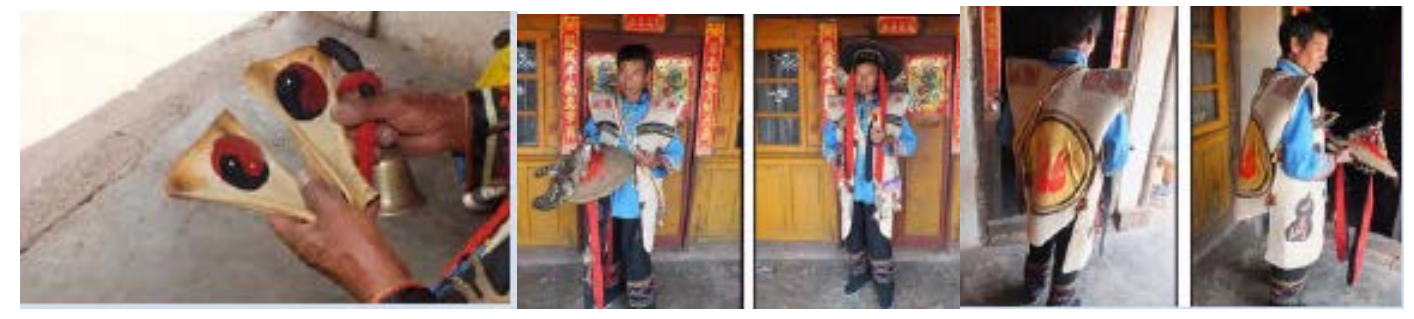

Fig. 1. Bimo Culture of Yi People

\section{Residential Culture}

The houses of Yi people are mainly built in cob-wood structure. Limited by environmental and economic conditions, the houses can be divided into the following types, namely cob house with antefix, thatched house, shack, house with wood block tile, etc. All these types of houses have a similar courtyard, as shown in Figure 2.

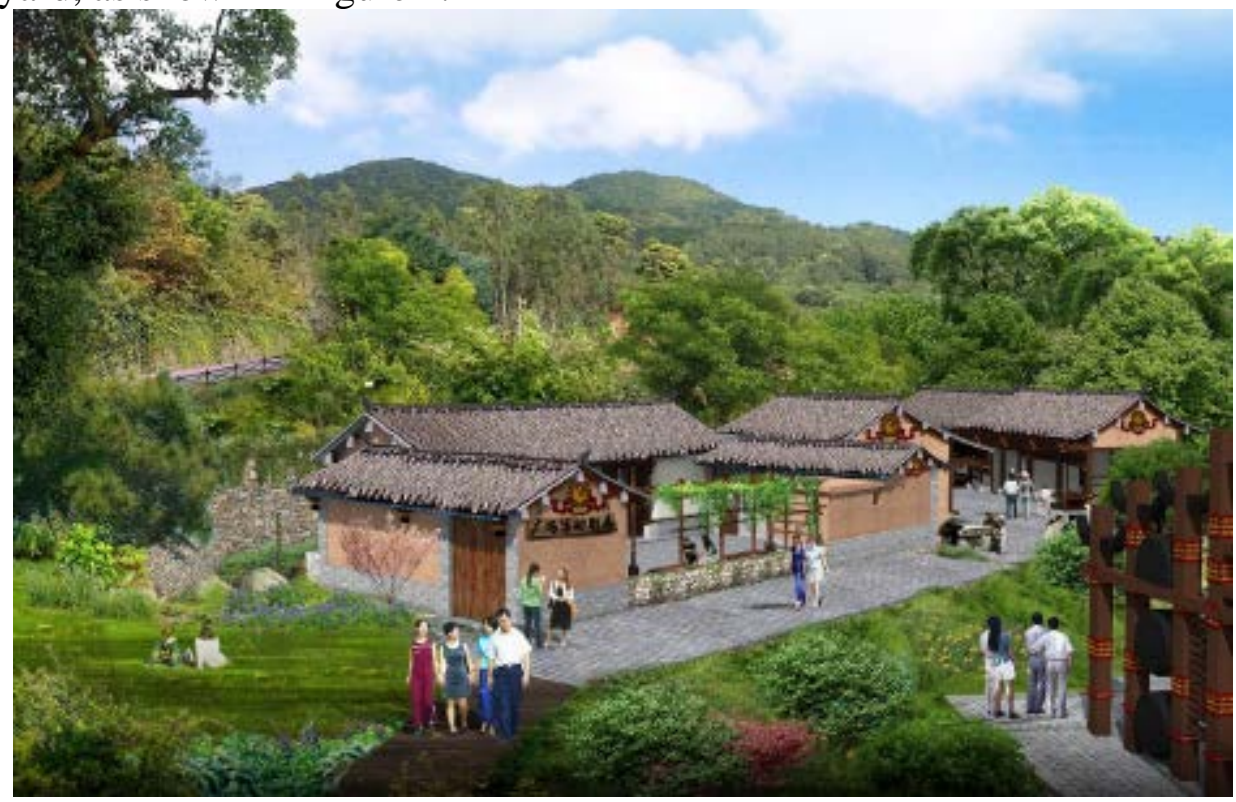

Fig. 2. Design Sketch of House of Yi People

\section{Dress Culture}

The most prominent characteristic of the dress of people in Chuxiong lies in the exquisite, nice-looking decorative patterns with full-bodied ethnic culture on the top fly, sleeves, collar, waist, etc., which are mainly in red, black and green. As shown in Figure 3 below, the clothes of women are mainly made of white or cyan cloth, with lace on the collar and sleeves. The women like wearing silver jewelries, including bracelet, earring, etc. The embroidery lace on the clothes is the typical characteristic of the dress of Yi people, which was premade first, and then edged on the clothes, to achieve the best artistic effect. 


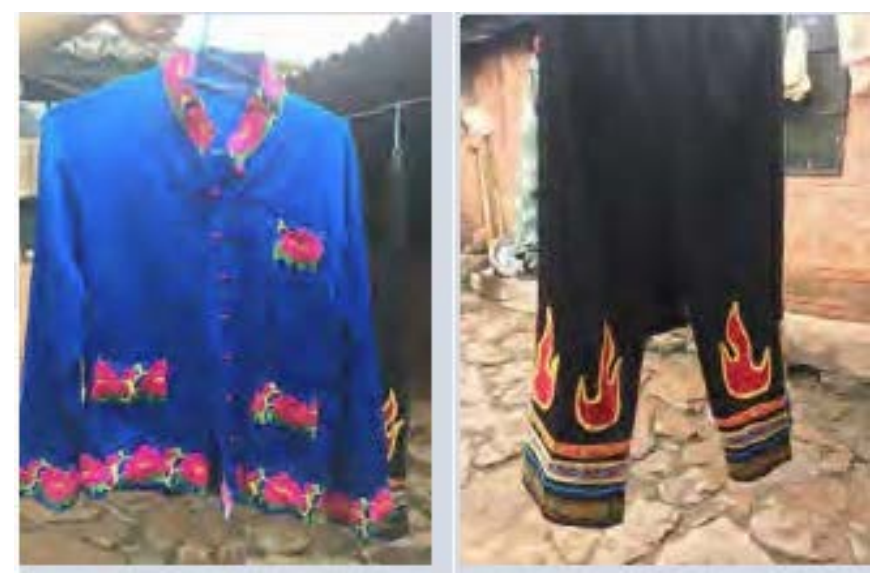

Fig. 3. Traditional Dress of Young Man of Yi Group

\section{Taboo}

Due to the indoctrination of traditional religious culture, there are many taboos in the life of Yi people, which is also an important part of the cultural landscape in Yi villages. The taboos include doing farm work on festivals (such as the Spring Festival, the Torch Festival, etc.,) woman's plowing fields, having a musical dialogue or making jokes too far in other person's house, addressing the elder disrespectfully by name, and going out walking in the night, etc.

\section{Features of Cultural Landscape in Yi Villages in Chuxiong in Yunnan}

\section{Site Selection and Rational Layout of Village}

Generally, the selection of Yi village site in Chuxiong is closely linked with the production method and life style of Yi people. The selection and layout of villages of Yi people show that Yi people tend to build their villages on the adret slope, which is fronting water and with hills on the back, and where people can farm in the front of village and raise or pasture livestock. The building layout in villages will be designed according to the hill shape, and most villages adopt a row-form layout, and a few adopt a distributed arrangement. Row-form layout can ensure ventilation and lighting, and makes for water discharging, providing certain convenience to people in daily life. Particularly, the Lifang Village was built by taking advantages of topography, and developed freely along with the river, without any rigid planning. The buildings were arranged naturally and freely, and harmonize with nature, having reflecting the pursuit of Yi people in daily life.

\section{Local Architectural Style}

The local religious thought and custom culture also have affected the design and architecture of Yi people. The architecture of Yi people organically combines the traditional culture and the state of environment development together, having realized the harmony and unity between the material pursuit and the spiritual pursuit, and then between human and nature, which is an irreplaceable element of Chinese architectural culture. Traditionally, there are few high buildings constructed in Yi villages, so that the vision is broad there, and the effect of culture and art thereof is relatively better ${ }^{[2]}$. Standing in the open yard in the dwelling of Yi people, you will feel close to nature, taste the smell of nature, and be spiritually comforted. Furthermore, the plants and flowers growing in the yard of Yi people's dwellings help people to cheer and cultivate emotions, showing the thought of oneness of man and nature to a certain extent, and favorable for the inheritance and development of the garden landscape culture of Yi people in modern society. 


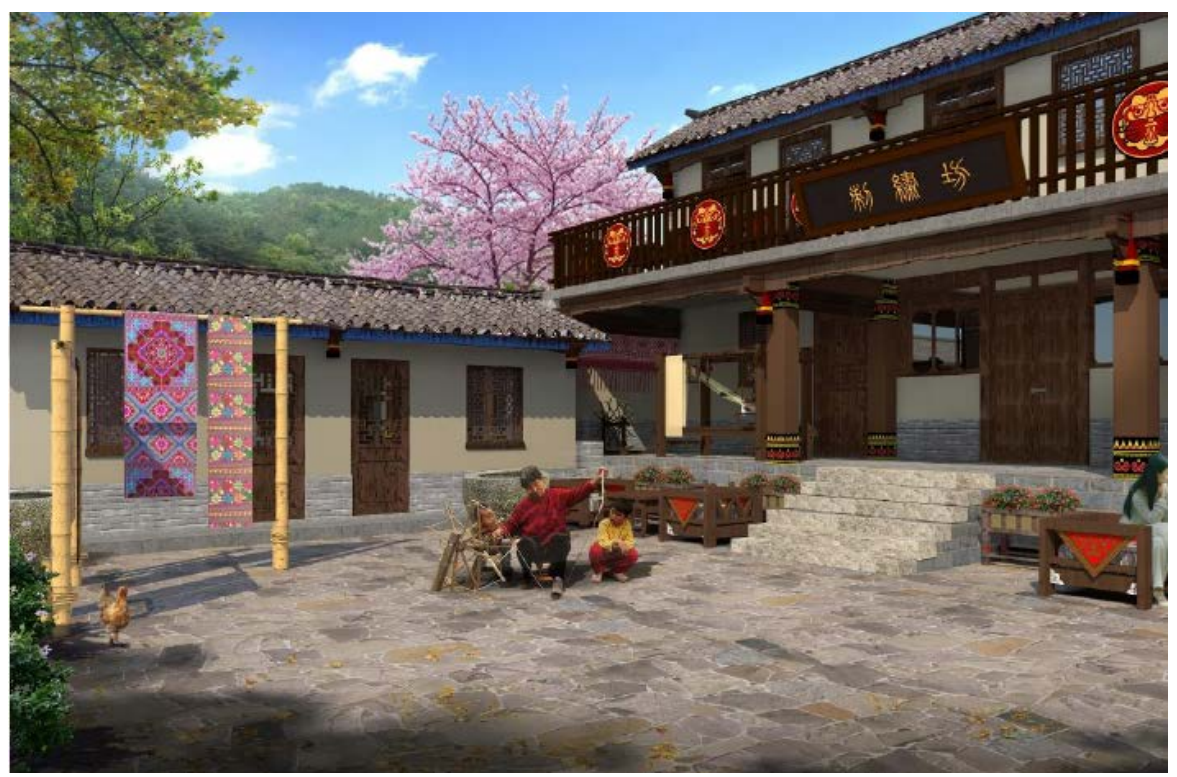

Fig. 4. Schematic Diagram of Open Yard of Dwelling of Yi People

\section{Indigenous Plant Culture}

Due to natural and historical reasons, the species of ancient animal and plant in Yi villages in Chuxiong that survive are little. Regarded as sacred plants in Tazhimo Village, the oak trees and kketeleeria fortunei there are preserved well, of which the history is said to be as long as one hundred years. Similarly, the ancient cypresses, regarded as the geomantically treasured tree in Jiutai Village, also are preserved well, which are still important to local villagers today. It shows that the survival of the ancient trees in $\mathrm{Yi}$ villages is mainly due to their cultural connotations, which have been remaining important in local people's heart no matter how the society evolves, and then protected by local people. This is another influencing factor of the landscape culture of Yi villages.

\section{Folk Culture}

The characteristics of the folk culture of the cultural landscape in Yi villages in Chuxiong are mainly reflected in three aspects, namely religious culture and thought, dress culture, and folk art culture. First, Yi people always take traditional religious culture seriously. Hardly affected by the external environment, the ancestor-worshipping rituals have been completely preserved, which reflects the worship of $\mathrm{Yi}$ people to ancestors in religious activities, and has greatly affected the inheritance and development of village culture of Yi people. The core religious thought of Yi people is that they believe that their ancestors who passed away will protect and bless them in another world, which is closely bound up with their fortune and misfortune. The ultimate spiritual pursuit of Yi people is that they can return to their origin after dying. All of their religious rites and rituals are thought by local people as an important means to send the died people back to their origin, and highly valued by local people ${ }^{[3]}$. Second, due to the geographic location, local economic conditions, and the influence of the cultural thoughts of Han people, most of the young men and women of Yi people become do not resolutely insist on wearing the folk dress any more. Besides, under the assimilation effect of the dress culture of Han people, some youth of Yi people begin to think that their folk dress is out of fashion, and then become less confident in the development of their folk dress. Both of the two phenomena above are unfavorable to the development of the inheritance of the folk dress culture of Yi people. Fortunately, the Yi people in some remote mountainous areas, seldom affected by the Han culture, still insist on wearing the traditional dress. The people in traditional dress look harmonious with nature. This shows that the thought of oneness of man and nature believed by Yi people is also reflected in the collocation and development of their dress. Third, people of the Yi group in Chuxiong all are good at singing and dancing. The tradition of singing and dancing of $\mathrm{Yi}$ people has a long history. Throughout the development of singing and dancing, they have organically combined the art of singing and dancing and local history, culture, living and production, to convey different ideas and emotions. 
As a whole, Chuxiong is an important gathering place of Yi people. The original folk tradition and culture have been preserved intactly in the form of opusculum. Towns with a long history where a large number of Yi people gather have been formed and developed there. The cultural landscape in Yi villages have combined with the traditional culture of Yi people together, both of which mutually affect and impact each other. Thus, the cultural landscape in Yi villages has gradually become one of the most typical cultural landscapes with local characteristics, of great significance to the research of local and nationwide garden art design.

\section{Reference to the Elements of the Unique Traditional Cultural Landscape of Yi People in the Construction of Modern Gardens}

\section{Reference to the Unique Traditional Cultural Landscape in the Construction of the Ten-month Solar Calendar Culture Garden in Chuxiong}

The ten-month solar calendar culture garden is a unique traditional culture garden with the characteristics of the Yi ethnic group, where the traditional cultural landscape elements and the design concept of modern garden architecture have been integrated together, showing the unique style of landscape architecture of Yi people. Themed by the ten-month solar calendar, the traditional calendar of the Yi ethnic group, and integrating the research of the traditional ethnic culture, the exchange of ethnic arts, the performance of ethnic customs, and business activities, the ten-month solar calendar culture garden was built for exhibiting the culture heritages of Yi people, the essence of cultures and arts of Yi people accumulated through the long history progress ${ }^{[4]}$. In the culture garden, the elements of cultural landscape of Yi village can be seen everywhere, which are presented with modern layout. For example, the log houses and thatched pavilions are arranged in a scientific layout. The totems of Yi people, such as tiger, ox-head, cucurbit, etc., have been integrated into different landscape architectures, and a large amount of representative indigenous plants of Yi culture are growing in the yard in a rational manner, like rhododendron delavayi, camellia, etc., making for the spread and inheritance of the traditional culture of Yi people in modern society in a wider range.

\section{Traditional Village of Yi People Built in the Ethnic Villages of the P.R.C. in Yunnan}

In the ethnic villages of the P.R.C., the cultural landscape of Yi villages is presented. In the Yi village in the ethnic villages, cob house in black, red and yellow (the favorite colors of Yi people), the traditional dwelling building form of Yi people, is the main type of building ${ }^{[5]}$. In respect of totem, tiger and ox have been selected and applied. Besides, the elements of cucurbit sheng, the unique instrument of Yi people, and the ancient calendar, solar-calendar, are showed, having a certain positive effect on the inheritance of the traditional cultural landscape of Yi people and the application thereof in modern society.

\section{Conclusion}

In conclusion, the research on the traditional landscape elements of Yi people in is far from enough presently, and the excellent traditional culture elements in the landscape design of the Yi ethnic group also have not been widely applied in the design of modern gardens, which is not favorable for both the inheritance of the traditional garden architecture culture of Yi people and the diversity of Chinese landscape design. Therefore, it is necessary to put more efforts in the research of the cultural landscape elements of Yi villages, and apply these elements in the artistic design of modern gardens in combination with the idea of modern garden architecture, so as to inherit the unique landscape culture of Yi people more completely while enriching the design concept and resources of Chinese garden arts.

\section{References}

[1] LI Jinfa. Influence of Generation Gap on Village Culture of Yi Ethnic Group- Tachong Village (in the Central Region of Yunnan Province). Journal of Bijie University: Integrated Science, 2011, 29(12): 26-29. 
[2] WAN Yi. Intangible Cultural Heritage Protection of Traditional Sports in the Change of Village Community Structure-A' Xi Dance in the Moon of Yi People in Keyi Village in Mile County. China Sports Science, 2011, 31(2): 12-18, 35.

[3] YANG Guocai. Post-earthquake Reconstruction and Tourism Development of Zhugeying Village (A Millennium Yi Village in Chuxiong)- Enlightenment of Village Development after Geological Disaster and Sociological Reflection thereon. Journal of Yunnan University for Nationalities (Philosophy and Social Science), 2011, 28(5): 78-85.

[4] LI Cuiling. Religious Faith and Ethnic Identity in Hu Village under the Marketization, A Village Inhabited by Yi People and Han People. Social Sciences in Yunnan,2013(1):20-24.

[5] LIU Sipeng. Research on Modern Social Function of Mythology of Yi Ethnic Group in Liangshan-Xiangfang Village in Weicheng Town in Yanyuan County. Sichuan Normal University, 2015. 